\title{
Increased Behavioral Variation and the Calculation of Release Numbers for Reintroduction Programs
}

\author{
M. ELSBETH MCPHEE* AND EMILY D. SILVERMAN \\ School of Natural Resources and Environment, University of Michigan, 430 E. University, Ann Arbor, MI 48109-1115, U.S.A.
}

\begin{abstract}
Captive populations can exhibit more behavioral variation than their wild counterparts as a result of relaxed selective pressures in the captive environment. This increased variation can translate into decreased survivorship upon reintroduction to native habitats. Data show that captive populations of oldfield mice (Peromyscus polionotus subgriseus) exhibit such an increase in variation. Motivated by these results, we developed a series of calculations for a "release ratio" that can be used to determine the number of captive-bred animals needed to compensate for the increased variance. We present calculations of release ratios for behavioral and morphological variables with different distributions and illustrate the functional relationship between release numbers, increased variation, and change in average behavior and morphology. Our calculations indicated that the release of 130-150 captive-bred oldfield mice is equivalent to the release of 100 wildlike animals. Release ratios will vary among species, however, and perhaps among different populations of the same species and should be calculated separately for each situation. Development of the release ratio is the first rigorous effort to incorporate behavioral and morphological changes due to captivity into reintroduction planning. Release ratios will belp conservation biologists ensure that the appropriate number of animals is released, thus increasing the success of reintroduction programs.
\end{abstract}

Variación Conductual Incrementada y el Cálculo del Número de Liberaciones para Programas de Reintroducción

Resumen: Las poblaciones cautivas pueden exbibir mayor variación conductual que sus contrapartes silvestres como resultado del relajamiento de presiones selectivas en el ambiente de cautiverio. Esta variación incrementada puede traducirse en una disminución de la supervivencia en la reintroducción a hábitats nativos. Hay datos que muestran que poblaciones cautivas de ratones Peromyscus polionotus subgriseus exhiben tal incremento en la variación. Motivados por estos resultados, desarrollamos una serie de cálculos para un "índice de liberación" que pueda utilizarse para determinar el número de animales criados en cautiverio requerido para compensar la variación incrementada. Presentamos los cálculos de 2 índices de liberación para variables conductuales y morfologicas con distribuciones diferentes e ilustramos la relación funcional entre el número de liberaciones, la variación incrementada y el cambio en la conducta promedio y la morfología. Nuestros cálculos indicaron que la liberación de 130 a 150 ratones es equivalente a la liberación de 100 animales silvestres. Sin embargo, los índices de liberación varían entre especies y quizás entre poblaciones diferentes de la misma especie y deben calcularse por separado en cada situación. El desarrollo de índices de liberación es el primer esfuerzo riguroso para incorporar cambios conductuales y morfológicos debido al cautiverio en la planificación de reintroducciones. Los índices de liberación ayudarán a que los biólogos de la conservación se aseguren que el número de animales liberados es el apropiado, incrementando con ello el éxito de los programas de reintroducción.

*email mmcphee@umich.edu

Paper submitted November 5, 2002; revised manuscript accepted September 17, 2003. 


\section{Introduction}

As wildlife populations have continued to decline, the number of captive breeding and reintroduction programs aimed at conserving endangered wildlife has increased. The efficacy of these programs, however, has been debated (Griffith et al. 1989; Kleiman 1989; Chivers 1991; Stuart 1991; Lindburg 1992). A survey of reintroductions found that only 16 of 145 programs (11\%) showed measurable success (Beck 1995). Often, specific behavioral deficiencies account for the mortality of reintroduced individuals. For example, in reintroductions of the golden lion tamarin (Leontopithecus rosalia), some individuals failed to survive because their locomotor skills were deficient, they could not orient themselves spatially, and they were not able to recognize natural foods, nonavian predators, and dangerous nonpredaceous animals (Kleiman et al. 1990). Similarly, in Madagascar, reintroduced black and white ruffed lemurs (Varecia variegata variegata) failed to avoid predators, find food, negotiate and locomote in a complex arboreal environment, and recognize appropriate habitat (Britt et al. 1999). Reintroduced Thickbilled Parrots (Rhynchopsitta pachyrhyncha) suffered high mortality because they did not flock appropriately and could not keep up with wild individuals. Released parrots therefore experienced high predation rates and poor nutrition even though they had been parent-reared and trained prior to release (Wallace 1994). Likewise, reintroductions of African wild dogs (Lycaon pictus) failed in part because released individuals were unable to avoid lion predation or to capture their own prey (Mills 1999; Frantzen et al. 2001).

These examples illustrate the importance of natural behavior in captive-bred animals to reintroduction success. The selective pressures associated with a captive environment can affect many behaviors because these pressures are often quite different from those under which a species evolved (Darwin 1868; Price 1970; Frankham et al. 1986; Lickliter \& Ness 1990; Stunz \& Minello 2001). Novel selective pressures can cause the variability and average expression of population traits to shift. Such shifts suggest that individual animals may not survive reintroduction because their behaviors are appropriate for captivity, not the wild environment. Unless individuals with behaviors similar to wild animals can be preferentially released, an increased number of captive-bred individuals will need to be reintroduced to meet a targeted wild population size.

We developed a method to estimate the size of a release population, defining the "release ratio" as the number of individuals that should be released to compensate for increased variation in a given trait of the captive population. Because morphology can directly affect an individual's ability to perform certain behaviors, we also considered morphological traits. Our calculations are the first to incorporate behavioral and morphological changes due to captivity into a quantitative determination of release population size. We present calculations based on the distribution of the trait of interest and the ratio of the release population's trait variance to that of the wild population. We considered traits that have normal, exponential, and beta distributions. We also considered the case in which the trait distribution is unknown. We illustrated the calculations for each distribution with examples from a study of oldfield mice (Peromyscus polionotus subgriseus) (McPhee 2002, 2004).

These calculations assume that data are available for both captive-bred and wild populations. If data from the wild population are not available, scientists may want to compare release animals to recently captured conspecifics or to wild individuals of a closely related species. Therefore, we call this comparison population-wild or otherwise-the baseline population.

\section{Methods}

\section{Calculating the Release Ratio}

To calculate the release ratio, we first defined the traits of interest and specified their distributions. Second, we determined the range of trait values associated with high survival rates in a wild environment, the target-trait range. For example, the target-trait range may be \pm 2 baseline standard deviations about the baseline mean or $\leq 1$ baseline standard deviation above the baseline mean. We included examples where the preferred range of traits was centered on the baseline mean, as well as in one tail of the trait distribution.

The release ratio was calculated as

$$
R=\frac{P_{b}}{P_{r}}
$$

where $P_{b}$ is the proportion of the baseline population that falls within the target-trait range and $P_{r}$ is the proportion of the captive-bred release population that falls within that same range. This ratio was determined by equating the expected number of baseline animals in the targettrait range with the expected number of release animals in the range: $N_{r} P_{r}=N_{b} P_{b}$. For example, if $R=2$ and $P_{b}=$ 0.9 , then in a release of 200 individuals one would expect 90 animals in the target-trait range, which is identical to the number expected in a wild population of 100 . If the program required 100 release animals in the target-trait range, then it would need to release 223 animals.

A more conservative calculation specified $R$ such that the probability that a single baseline animal is in the targettrait range, $P_{b}$, equaled the probability that at least one of each $R$-released animals was in the range. In this case,

$$
R=\frac{\ln \left(1-P_{b}\right)}{\ln \left(1-P_{r}\right)} .
$$


In the example above, $P_{r}=0.45$ because $P_{b}=0.9$ and $R=2$. Here, if $P_{b}=0.9$ and $P_{r}=0.45, R=3.85$; in other words, four release animals are needed to ensure a probability of 0.9 that at least one is within the target-trait range.

In the calculations that follow, $X_{b}$ represent the trait variable of interest measured on an individual from the baseline population. It has mean $\mu_{b}$ and standard deviation $\sigma_{b}$. Similarly, $X_{r}$, the trait measurement on a release individual, has mean $\mu_{r}$ and standard deviation $\sigma_{r}$.

\section{Normally Distributed Traits}

Many trait variables (e.g., biometric measurements such as size or weight) follow a normal or normal-like distribution. Other variables that represent averages of repeated measurements might also be expected to follow a normal distribution. For such variables, one can calculate the proportion of observations that fall within a certain number (k) of standard deviations about the mean.

If $X_{b}$ and $X_{r}$ are normally distributed and the target-trait range includes $\pm \boldsymbol{k}$ baseline standard deviations about $\mu_{b}$, then

$$
\begin{aligned}
P_{b} & =\operatorname{Pr}\left[\mu_{b}-k \cdot \sigma_{b} \leq X_{b} \leq \mu_{b}+k \cdot \sigma_{b}\right] \\
& =\operatorname{Pr}[-k \leq Z \leq k]
\end{aligned}
$$

where $P_{r}$ is the proportion of release animals in the target trail range, and $Z$ has a standard normal distribution. The proportion of release animals that have trait values in the target range is

$$
\begin{aligned}
P_{r} & =\operatorname{Pr}\left[\mu_{b}-\boldsymbol{k} \cdot \sigma_{b} \leq X_{r} \leq \mu_{b}+k \cdot \sigma_{b}\right] \\
& =\operatorname{Pr}\left[\frac{\left(\mu_{b}-\mu_{r}\right)-\boldsymbol{k} \cdot \sigma_{b}}{\sigma_{r}} \leq Z \leq \frac{\left(\mu_{b}-\mu_{r}\right)+\boldsymbol{k} \cdot \sigma_{b}}{\sigma_{r}}\right] \\
& =\operatorname{Pr}\left[\left(\boldsymbol{k}^{\prime}-\boldsymbol{k}\right) \frac{\sigma_{b}}{\sigma_{r}} \leq Z \leq\left(\boldsymbol{k}^{\prime}+\boldsymbol{k}\right) \frac{\sigma_{b}}{\sigma_{r}}\right]
\end{aligned}
$$

where $\boldsymbol{k}^{\prime}=\left(\mu_{b}-\mu_{r}\right) / \sigma_{b}$ is the difference between the baseline and release means, expressed in units of the baseline standard deviation.

Figure 1 illustrates $P_{b}$ and $P_{r}$ for a normally distributed trait. The ratio of Eq. (3) to Eq. (4) provides the release ratio for normally distributed traits with a target-trait range symmetric about the mean. Figure $2 a$ presents a summary of $R$ as a function of $\sigma_{r} / \sigma_{b}$ for a variety of values of $\boldsymbol{k}^{\prime}$, when $k=1$, and the target-trait range is symmetric about the baseline mean. The ratio of the standard deviations, $\sigma_{r} / \sigma_{b}$, measures the degree of increased variability in the release population.

\section{Exponentially Distributed Traits}

Because biological data are often not normal, we developed calculations for two other distributions: the exponential and beta. We used the exponential distribution to model time-related variables such as the interval between events. The exponential density function is $f(x)=$

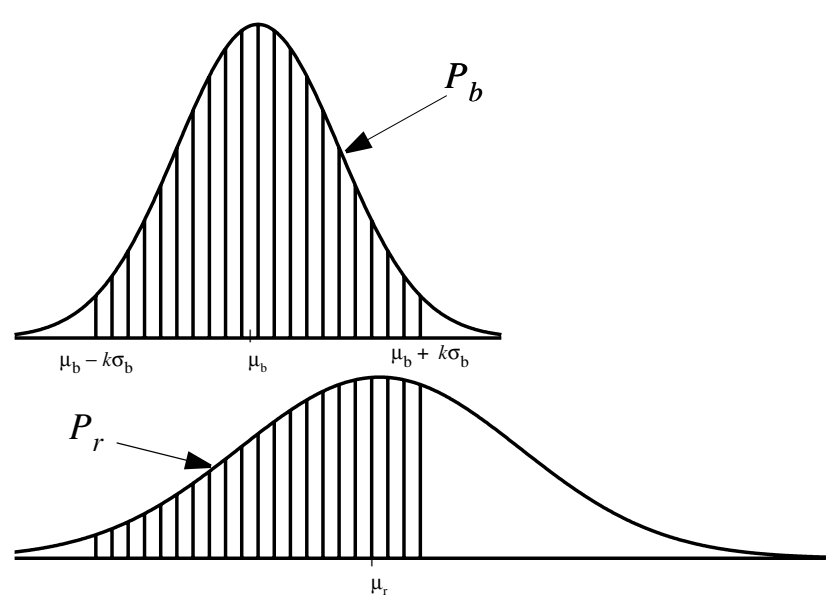

Figure 1. Proportion of the baseline population that falls within the target-trait range $\left(\mathrm{P}_{\mathrm{b}}\right)$ and proportion of the captive-bred release population that falls within that same range $\left(\mathrm{P}_{\mathrm{r}}\right)$ (batched portions) for a normally distributed trait. In this example, the mean and variance bave increased in the release population and the target-trait range falls about the baseline mean $\mu_{b}$. The $\mathrm{P}_{\mathrm{r}}$ has the same bounds as $\mathrm{P}_{\mathrm{b}}$ but is smaller because of the shift in distribution.

$\lambda e^{-\lambda x}$ for $x>0$. The sole parameter, $\lambda$, describes the rate at which the curve drops off, with small values most likely and $1 / \lambda=\mu=\sigma$.

For the normal distribution, we considered a target-trait range centered on the mean. We might instead want to calculate $R$ to ensure a sufficient number of individuals at one end of the trait distribution. For the exponential, if we define the target-trait range to be zero at $k$ standard deviations above the mean, $\left[0, \mu_{b}+k \sigma_{b}\right]$, which can be expressed as $\left[0,(1+k) / \lambda_{b}\right]$, then

$$
\begin{aligned}
P_{b} & =\operatorname{Pr}\left[X_{b} \leq \mu_{b}+k \cdot \sigma_{b}\right] \\
& =\operatorname{Pr}\left[X_{b} \leq(1+k) / \lambda_{b}\right] \\
& =1-e^{-(1+k)},
\end{aligned}
$$

and

$$
\begin{aligned}
P_{r} & =\operatorname{Pr}\left[X_{r} \leq \mu_{b}+k \cdot \sigma_{b}\right] \\
& =1-e^{-(1+k) \mu_{b} / \mu_{r}} .
\end{aligned}
$$

Thus, the release ratio is

$$
R=\frac{1-e^{-(1+k)}}{1-e^{-(1+k) \mu_{b} / \mu_{r}}}
$$

Figure 2b illustrates the release ratio as a function of $\boldsymbol{k}$ and $\sigma_{r} / \sigma_{b}=\mu_{r} / \mu_{b}$ for a target-trait range in the lower tail of the distribution. 

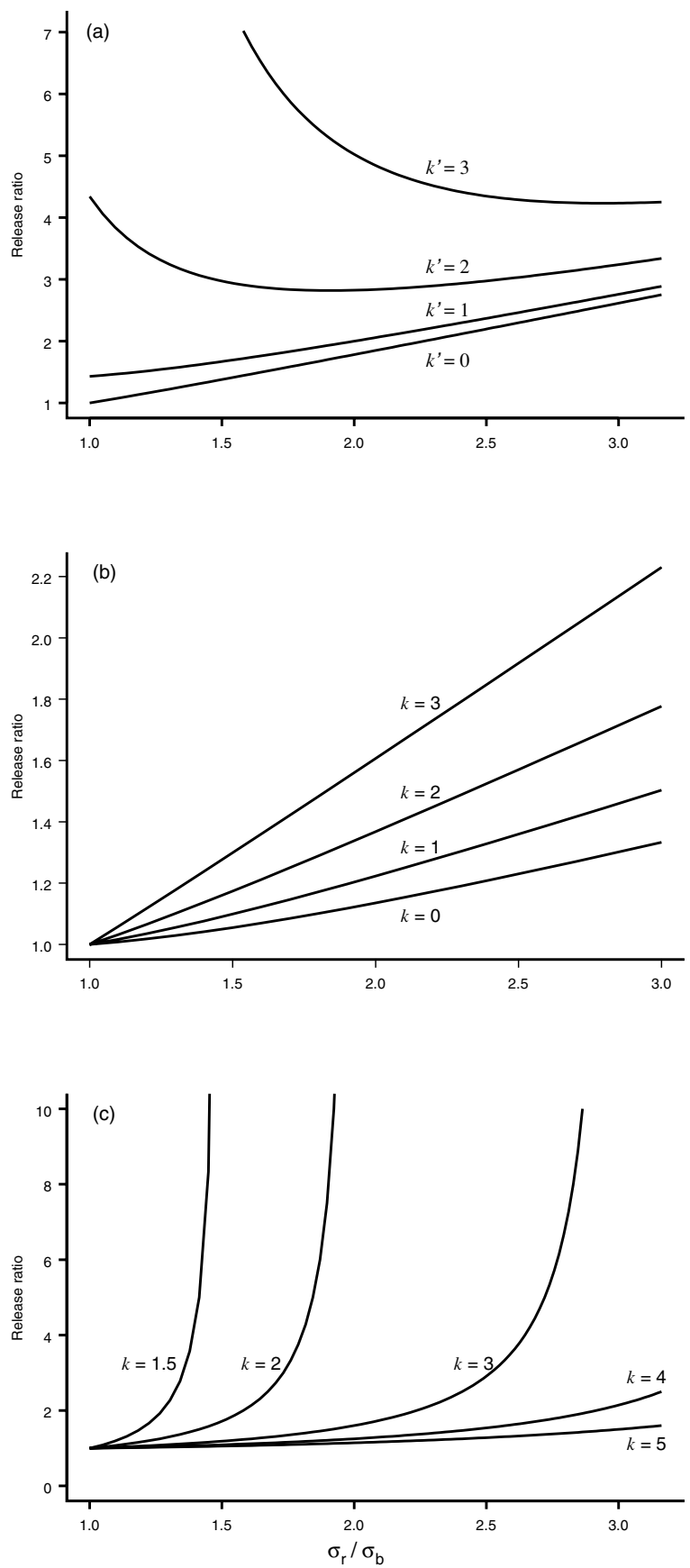

Figure 2. Release ratios as a function of $\sigma_{\mathrm{r}} / \sigma_{\mathrm{b}}$ for (a) a normally distributed trait variable, (b) an exponentially distributed trait variable, and (c) a trait with an unknown distribution. Variables are defined in Methods. (a) Release ratio for $\mathrm{k}=1$; each curve represents a different value of $\mathrm{k}^{\prime}$. For example, if $\sigma_{\mathrm{r}} / \sigma_{\mathrm{b}}$ $=2$, the release population's standard deviation is twice that of the baseline population. In this case, if the release population mean is also $2 \sigma_{\mathrm{b}}$ larger than the baseline mean, then $\mathrm{k}^{\prime}=2$ and $\mathrm{R}=3$. Therefore, three times as many release animals are necessary to ensure that an equal number of baseline and release

\section{Beta-Distributed Traits}

Some trait variables take values between zero and one, such as proportions. For these, the beta distribution may be a useful descriptor. This distribution has two parameters, $a$ and $b$, that can be expressed in terms of the mean and variance as

$$
\begin{gathered}
a=\frac{\mu^{2}(1-\mu)}{\sigma^{2}}-\mu, \\
b=\frac{\mu(1-\mu)^{2}}{\sigma^{2}}-(1-\mu) .
\end{gathered}
$$

A beta distribution can take many different shapes, depending on the values of $a$ and $b$. Thus, the target-trait range should take into account the specific beta distribution and the variable being measured. As with the normal distribution, $P_{b}$ and $P_{r}$ must be looked up in a published table or calculated with statistical software.

\section{Unknown Trait Distribution}

If a variable's distribution is not described well by a standard distribution, the release ratio can be estimated with Chebyshev's inequality. This calculation, however, will be more conservative than a release ratio calculated for a known distribution. Chebyshev's inequality states that, for a random variable $X$, with mean $\mu$ and standard deviation $\sigma$,

$$
\operatorname{Pr}[|X-\mu|>k \sigma] \leq \frac{1}{k^{2}}
$$

(Everitt 1998). Chebyshev's inequality gives a lower bound on the proportion of observations within $k$ standard deviations of the mean: for $k=2$, Eq. 10 tells us that no more than $25 \%$ of the observations are farther than two standard deviations from the mean; alternatively, at least $75 \%$ are within $2 \sigma$ of $\mu$.

Calculation of the release ratio in this case is restricted in several ways. First, one can only consider target-trait ranges centered on the mean. Second, because Chebyshev's inequality provides a lower bound on the proportion of individuals within the target-trait range, when the difference between $\sigma_{r}$ and $\sigma_{b}$ is large, the estimated release ratio will not be finite for reasonable values of $k$

animals fall within the target-trait range of $\mu_{\mathrm{b}} \pm 2 \sigma_{\mathrm{b}}$. (b) Each curve represents a different value of $\mathrm{k}$. For example, if $\sigma_{\mathrm{r}} / \sigma_{\mathrm{b}}=2$ and $\mathrm{k}=2$, then $\mathrm{R}=1.37$, and almost three release animals are necessary to ensure that two fall within the target-trait range. (c) Each curve represents a different value of $\mathrm{k}$. For example, if $\sigma_{\mathrm{r}} / \sigma_{\mathrm{b}}=1.6$, twice as many release animals are necessary to ensure that the same number of animals fall within $2 \sigma_{\mathrm{b}}$. 
(i.e., the inequality provides no useful information about $R)$. This problem also affects the calculation of $R$ for unequal means. In this case, the target-trait range is not symmetric about $\mu_{r}$, and two different values of $k$ must be computed. For reasonable differences in the release and baseline means and standard deviations, the inequality provides no upper limit on the release ratio. Thus, we present results for the case when $\mu_{b}=\mu_{r}=\mu$.

For a baseline population with mean $\mu$ and standard deviation $\sigma_{b}$, Chebyshev's inequality states that

$$
P_{b}=1-\operatorname{Pr}\left[\left|X_{b}-\mu\right|>k \sigma_{b}\right] \geq 1-\frac{1}{k^{2}}
$$

and, for a release population with the same mean,

$$
\begin{aligned}
P_{r} & =1-\operatorname{Pr}\left[\left|X_{r}-\mu\right|>k \sigma_{b}\right] \\
& =1-\operatorname{Pr}\left[\left|X_{r}-\mu\right|>\frac{k \sigma_{b}}{\sigma_{r}} \cdot \sigma_{r}\right] \geq 1-\frac{\sigma_{r}^{2}}{k^{2} \sigma_{b}^{2}} .
\end{aligned}
$$

Chebyshev's inequality provides no information on $P_{r}$ when $\sigma_{r}^{2} \geq k^{2} \sigma_{b}^{2}$. The estimated release ratio is

$$
R=\frac{1-1 / k^{2}}{1-\sigma_{r}^{2} / k^{2} \sigma_{b}^{2}}
$$

The true value of the ratio depends on the values of $P_{b}$ and $P_{r}$ and not their lower bounds. Replacing the numerator in equation 13 with 1 gives an upper estimate of $R$ (when $P_{b}$ in Eq. 11 is well above its lower bound); this assumes that all baseline individuals and the lower bound of release individuals are within the target range.

Figure 2c shows the release ratio versus $\sigma_{r} / \sigma_{b}$ for several values of $k$. The steep portion of each curve occurs when $\sigma_{r} / \sigma_{b}$ is too large for the inequality to provide a useful estimate of $R$. Shifting to a larger value of $k$ gives a reasonable estimate of $R$ for a wider target-trait range.

The calculations presented in this section provide an upper bound on $R$ regardless of the underlying distribution. This is useful if one is not confident about the distributional assumption, for example, when sample sizes are small or the mean and variance are known only from the literature or other studies.

\section{Confidence Intervals for $\boldsymbol{R}$}

The formulas presented above all require knowledge of the population parameter values for both the baseline and release populations. In reality, $R$ is calculated based on estimates of these parameters. This substitution introduces uncertainty into the calculation of the release ratio. Release program managers may want to calculate potential bias in, and confidence intervals for, their estimate of $\boldsymbol{R}$ to account for this uncertainty.

We suggest parametric bootstrapping as a straightforward method to calculate bias and confidence intervals for $R$. This entails using the estimated parameter values for the baseline population to generate a sample of size $n_{b}$ from the hypothesized trait distribution and using the estimated parameters for the release population to generate a sample of size $n_{r}$. The $R$ is then calculated from the two bootstrapped samples. This procedure is repeated multiple times, resulting in a set of bootstrapped release ratios.

In the case of an unknown trait distribution, the confidence intervals are calculated with a nonparametric bootstrapping procedure. In this case, a random sample of size $n_{b}$ is drawn with replacement from the baseline observations, and a sample of size $n_{r}$ is chosen from the release observations. The $R$ is calculated based on the two bootstrapped samples and the process is repeated, as in the parametric case.

Bias is estimated as the difference between the mean of the bootstrapped values of $R$ and the original estimate of $R$. There are a number of methods by which to obtain confidence intervals from the resampled $R$ values. We estimated $95 \%$ confidence intervals with the bias-corrected percentile method based on 1000 bootstrapped samples (Manly 1997). When bias is zero, the estimated confidence interval was $\left[R_{0.025}^{*}, R_{0.975}^{*}\right]$, where $R_{\alpha}^{*}$ is the 100 $\alpha$ th quantile of the bootstrapped $R$ values. When bias was present, the $\alpha$ values were adjusted to take the bias into account (for details see Manly 1997). This method was chosen in preference over the method that Manly (1997) describes as the second percentile method because the bootstrap distributions were somewhat skewed to the right. In this situation, the bias-corrected percentile method gives confidence intervals with a larger upper bound and is therefore a more conservative method for release-ratio estimation. The bootstrap confidence intervals, and all other calculations in this paper, were conducted in S-Plus (Statistical Sciences 1999).

\section{Application: Peromyscus polionotus}

McPhee (2002, 2004) tested the effects of captivity by comparing predator response behaviors and skull morphology among four populations of oldfield mice collected from Ocala National Forest, Florida, between 1952 and 2000: wild caught, two generations removed from the wild, 14 generations removed, and 35 generations removed. Her studies showed that variability in trait expression increased with generations in captivity, suggesting that relaxed selection in the captive environment modified mandible size and predator response behaviors. The effects of captivity on behavior and morphology, and ultimately reintroduction success, is of particular concern for this species. Due to shrinking habitat and increased predation, five subspecies of $P$. polionotus are listed as endangered and one as threatened (U.S. Fish and Wildlife Service [USFWS] 2001; Wooten 2001). Recovery plans for these mice list captive breeding and reintroduction 
as specific goals (USFWS 1987, 1993, 2001; Holler et al. 1989).

Using the calculations described above, we determined a release ratio for $P$. polionotus. We based our calculations on $k=1$ because these mice are easy to breed in captivity, there were large numbers of captive-bred animals available, and they are relatively inexpensive to capture, maintain in captivity, and release. These factors suggest that we could be strict in our definition of a target-trait range, calculating a larger release ratio and releasing more animals than if we had chosen $k=2$ or higher.

In these examples, the baseline population consisted of wild-caught animals and captive-bred animals two generations removed from the wild. The release population was made up of animals 14 and 35 generations removed from the wild.

\section{Example Calculations}

McPhee (2002) found that mean mandibular centroid size (a morphometric quantity) did not change significantly with generations in captivity $\left(\bar{x}_{b}=15.82, \bar{x}_{r}=15.90\right)$, but mandible size in the release population was more variable than in the baseline population $\left(s_{b}{ }^{2}=0.37, s_{r}{ }^{2}=\right.$ 0.65). The Kolmogorov-Smirnov goodness-of-fit test (Zar 1999) did not reject the null hypothesis of a normal distribution for either the release or baseline population $(p>$ $0.4, n_{b}=33, n_{r}=25$ ).

Because the means were equal, $k^{\prime}=0$ and, for $k=1$, $P_{b}=0.68$ and $P_{r}=0.55$. This gives an $R$ of 1.24 . To expect 68 release animals in the range $R$, one must release 124 individuals. Estimated bias for $R$ based on the parametric bootstrap samples was 0.06 , and the $95 \%$ confidence interval was $0.92,1.70$.

McPhee (2004) measured the amount of time in seconds that it took a mouse to enter a burrow after seeing a simulated predator (an owl silhouette). Generations in captivity significantly increased the mean and variance of time to burrow. These data appear to be exponentially distributed: the sample mean and standard deviation were close in value (Fig. $3 \mathrm{a}, \mathrm{b}, \bar{x}_{b}=9.68, s_{b}=8.45, \bar{x}_{r}=$ $15.18, s_{r}=14.65$ ), and the null hypothesis of an exponential distribution was not rejected for either population (Kolmogorov-Smirnov test, $p>0.1, n_{b}=37, n_{r}=34$ ). For McPhee's time to burrow data, the release ratio for $k=$ 1 is 1.20 (for $k=0$ and $2, R=1.34$ and 1.11 , respectively). The bootstrap-estimated bias for $R$ was 0.07 and the $95 \%$ confidence interval was $1.00,1.36$.

McPhee (2004) also measured refuge use in the oldfield mouse after presentation of a simulated predator. Refuge use entailed hiding in a burrow or under the food dispenser. Observations of location within the testing arena were noted every 2 seconds for 1 minute, for a total of 30 observations per mouse. These time-limited data were constrained to fall within the range 0 to 30 and are candidates for description by the beta distribution.
The proportion of observations that release animals were in a refuge was significantly lower than the proportion of observations for the baseline animals. Variance, however, was greater in the release than in the baseline population $\left(s_{b}^{2}=0.083, s_{r}^{2}=0.126\right.$; Fig. 3b). Most of the animals spent a high proportion of observations in the refuge after having seen the simulated predator, but, on average, release animals were observed in a refuge less often than baseline animals (Figs. 3c,d \& 4).

Using the means and variances for the refuge-use data, we estimated the parameters of the beta distribution: $x_{b}=0.758$ and $s_{b}{ }^{2}=0.083$ give an estimated $a$ of 0.918 and an estimated $b$ of 0.293 for the baseline population; $x_{r}=0.604$ and $s_{r}{ }^{2}=0.126$ give an estimated $a$ of 0.541 and estimated $b$ of 0.355 for the release population. Figure 4 illustrates the associated beta functions. The beta distribution was rejected for both populations (KolmogorovSmirnov test, baseline $p=0.001, n_{b}=45$; release $p=$ $\left.0.049, n_{r}=55\right)$. In both cases, rejection was due to too few values at 1 and too many just below 1 . We believe this was due to rounding errors in data recording and, in some cases, a delay in a mouse's detection of the predator. Discounting this discrepancy at 1 , the beta distribution was not rejected for either population $(p>0.1)$.

Animals that spend more time in a refuge in the presence of a predator should have higher rates of survival than those more accessible to the predator. Therefore, the target-trait range should be values larger than $k$ standard deviations below the mean, (i.e., $\left[\mu_{b}-\mathrm{k} \sigma_{b}, 1\right]$ ). Using the estimates of $a$ and $b$, we calculated $P_{b}=0.81$ and $P_{r}=0.76$ for $k=1$, giving a release ratio of 1.07 . The bias in $R$ in this case was estimated to be 0 and the $95 \%$ confidence interval was $1.01,1.13$.

In the Peromyscus study, the center of the tank was a vulnerable place because it was the farthest point from any refuge. Animals that did not decrease their use of the tank's center after exposure to a simulated predator would be less likely to survive in the wild. Although mean change in use of the middle of the tank as a function of the predator presentation did not differ significantly between the release and baseline populations $\left(\bar{x}_{b}=-0.037, \bar{x}_{r}=\right.$ 0.018 ), variance increased significantly (McPhee 2002; $\left.s_{b}^{2}=0.023, s_{r}^{2}=0.096\right)$. Because mean change was not significantly different from 0 , we used $\mu=0$. In the case of a trait with an unknown distribution, the value of $k$ was constrained by the ratio of standard deviations. Given that $s_{r} / s_{b}$ was 2.02 , the lowest possible $k$ we can consider was 3 . When $k=3, R \approx 1.63$, with an estimated bias of 0.76 and a $95 \%$ confidence interval of $1.05,9.88$; when $k=4, R \approx 1.26$, with an estimated bias of 0.27 and a $95 \%$ confidence interval of $1.03,2.74$ (Fig. 2c). The wide confidence interval and high bias for $k=3$ are due to the fact that some bootstrap samples have large values of $s_{r} / s_{b}$.

For the four traits we considered, the calculated release ratios for $P$. polionotus ranged from 1.07 to 1.63 and 
(a)

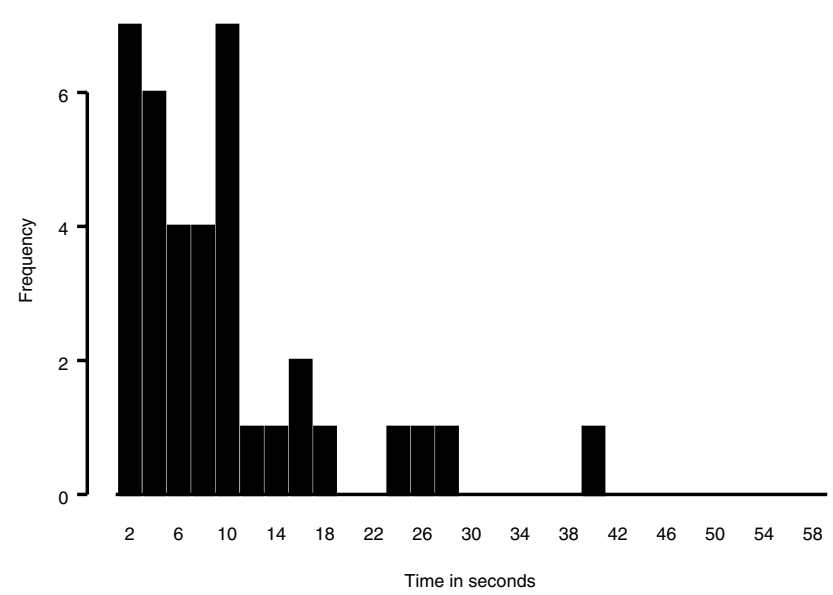

(c)

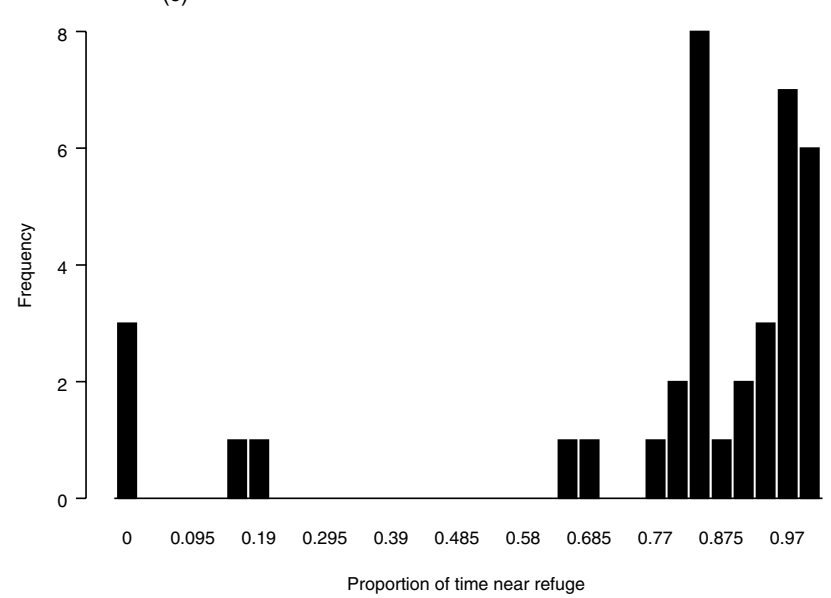

(b)

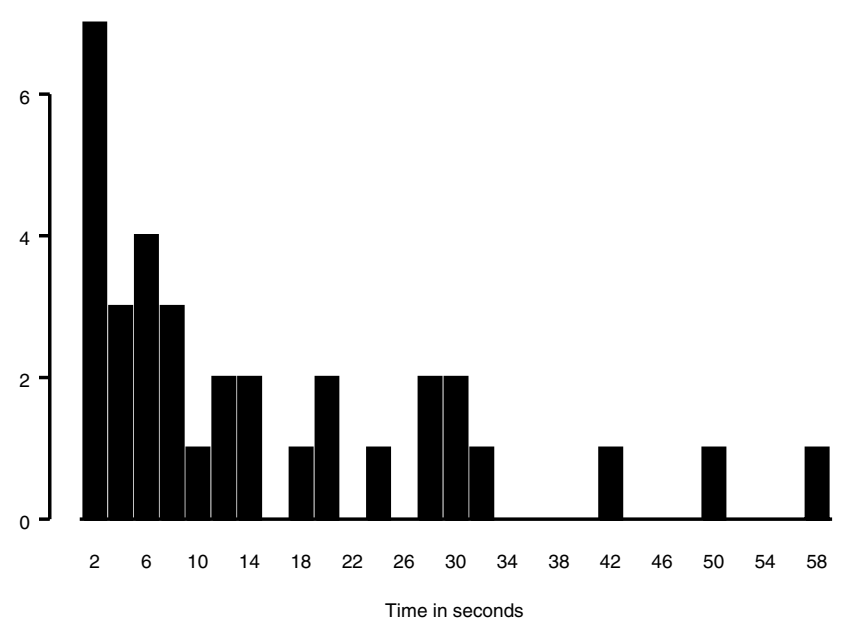

(d)

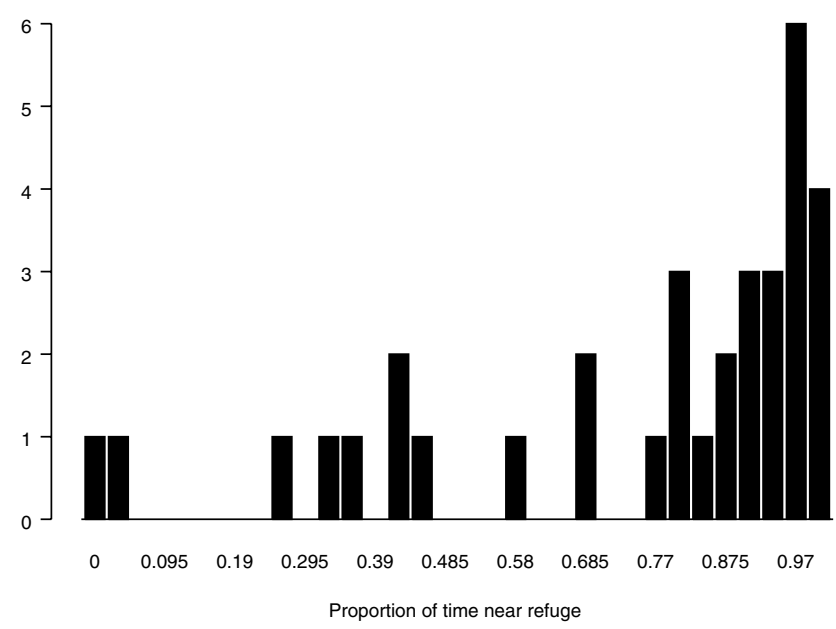

Figure 3. Time in seconds for (a) baseline and (b) release individuals to enter the burrow after exposure to a simulated predator $\left(\overline{\mathrm{x}}_{\mathrm{b}}=9.68, \overline{\mathrm{x}}_{\mathrm{r}}=15.18 ; \mathrm{s}_{\mathrm{b}}=8.45, \mathrm{~s}_{\mathrm{r}}=14.65\right)$. Proportion of observations that the (c) baseline and (d) release individuals spent in a refuge after exposure to a simulated predator $\left(\overline{\mathrm{x}}_{\mathrm{b}}=0.80, \overline{\mathrm{x}}_{\mathrm{r}}=0.62 ; \mathrm{s}_{\mathrm{b}}=0.08\right.$, $\left.\mathrm{s}_{\mathrm{r}}=0.12\right)$. Variables defined in Methods.

averaged to 1.28 , whereas the upper bounds on the $95 \%$ confidence intervals ranged from 1.13 to 9.88 . Excluding the upper bound for the Chebyshev calculations, which was quite extreme, these results suggest that managers would be acting conservatively if they released three oldfield mice for every two desired in the wild population.

\section{Discussion}

We have presented methods that incorporate increased variance into estimates of release population size for reintroduction programs and illustrate our calculations through behavioral observations of Peromyscus polionotus subgriseus (McPhee 2002, 2004). Current models that estimate population persistence and optimum release population size generally consider only genetic and demographic variables (e.g., Ginsberg 1994; Ballou \& Foose 1996; Ford 2002). Behavior and morphology of captivebred animals will affect survival, however, and should be incorporated into release decisions (Lacy 1987; Miller et al. 1990; Miller et al. 1994; McPhee 2004). Our work is the first rigorous and quantitative effort to incorporate behavioral and morphological change into release modeling.

Calculation of the release ratio entails specifying the traits of interest, their distribution, and target-trait ranges. This process depends on the species slated for reintroduction. Conservation biologists need to decide which traits are most relevant to survival and traits are measurable in their populations. The target-trait range will then be defined based on the trait distribution observed in wild populations and the program's logistical constraints. 


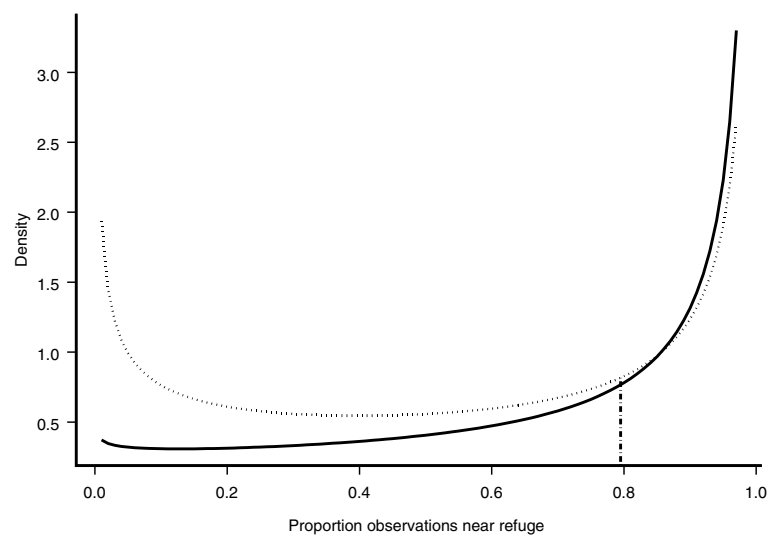

Figure 4. Proportion of observations of a mouse in a refuge after exposure to a simulated predator as modeled by the beta distribution. Solid line, baseline population; dashed line, release population.

\section{Trait Choice}

The traits of interest need to be determined a priori. The traits we used for $P$. $p$. subgriseus-mandible size, time to enter the burrow, use of a refuge, and change in use of the middle of the tank upon exposure to a simulated predator-were chosen for their biological relevance to survival in the wild and their measurability. Increased variance in mandible size was largely driven by tooth size, which could affect a released individual's ability to consume wild foods. The three behavioral variables all relate to an animal's ability to respond to predators. Calculating release ratios for a suite of traits within a single population, as demonstrated here, provides lower and upper bounds for $R$.

For species such as the black and white ruffed lemur and golden lion tamarin, the proportion of time spent at different heights within the forest (e.g., midcanopy, ground) and that spent foraging are critical variables because reintroduced animals have been deficient in these behaviors (Kleiman et al. 1990; Britt 1999). Studies have also shown marked differences between wild and hatchery-reared fishes: hatchery fish are deficient in recognizing predators, consuming live prey, and remaining cryptic (reviewed by Olla et al. 1998; Kellison et al. 2000; Sundström \& Johnsson 2001) and have significantly different brain morphologies than wild conspecifics (Marchetti \& Nevitt 2003). These traits are critical to survival in the wild and useful for release-ratio calculations for fishes. Additionally, efforts to establish a nonmigratory population of Whooping Cranes (Grus Americana) in Florida have been hampered by bobcat (Felis rutus) predation (Nesbitt et al. 2001) and aberrant foraging behaviors ( $M$. Kreger, personal communication). Appropriate foraging and predator-response behaviors are therefore important to reestablishment of this population.
The fundamental premise underlying calculation of the release ratio is the ability to compare the behavior and morphology of captive-bred and wild individuals. To date, however, there have been few quantitative studies of the effects of captivity on behavior and morphology, especially in mammals and birds (but see Kummer \& Kurt 1965; Rowell 1967; Price 1984; Myers et al. 1996; Biggins 2000; Höhn et al. 2000; McPhee 2004). Without more quantitative comparative studies and more information on the heritability of certain behaviors, choosing behaviors for use in calculating $R$ is difficult. Decisions about which traits are critical to survival should be based on (1) the problems observed in released populations of conspecifics or sister taxa, (2) the systematics and ecology of the taxon in question (Arnold 1995), and (3) the differences between long-term propagation sites and reintroduction sites (Arnold 1995). For example, if there is a greater variety of predators at the release site than the propagation site, then predator-response behaviors should be included in the calculation of $R$. With reintroduced Whooping Cranes, individuals have experienced high mortality as a result of behavioral deficiencies in captive-bred birds (Kreger 2003). Reintroduced cranes were observed foraging at night when bobcat predation was likely to be high. Experiments on captive and wild Sandhill Cranes (Grus Canadensis) that measure flush time in the presence of a predator and foraging as a function of time of day given ad libitum food could provide data for calculation of the Whooping Crane release ratio. The protocols developed could then be used for other endangered Gruiformes.

Collecting useful comparative data, however, is challenging because of variability in captive environments and husbandry techniques across captive institutions. For example, if foraging time in lemurs were the trait of interest, study animals would have to be housed in similar environments, fed consistently across institutions, and given a chance to forage as they would in the wild. Biologists need to develop protocols that allow rigorous comparisons of captive and wild populations. Such data will make reintroduction planning more efficient and effective.

\section{Distribution Identification}

Once trait variables have been determined, their distributions must be identified. The type of variable measured and the data in hand suggest the appropriate distribution to consider. The specific shape of a trait variable's distribution has important implications for calculation of the release ratio. Using calculations for one distribution when the data actually fit another could result in a substantial over- or underestimation of the release ratio. There are ramifications if the normal distribution is used when the exponential distribution is correct (Fig. 5) (e.g., if the normal distribution is used to calculate $R$ based on the number of seconds it took P.p.subgriseus to enter the burrow 


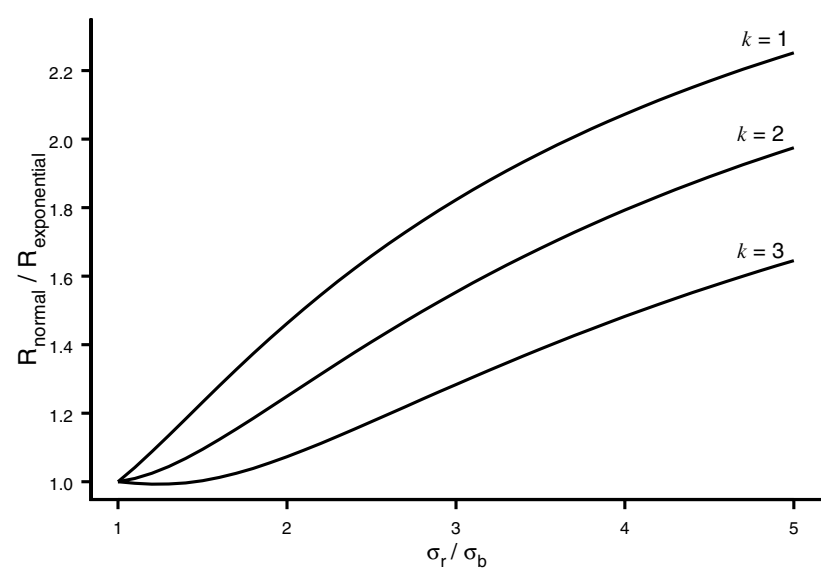

Figure 5. Ramifications of treating exponential data as normal. Release ratios of $\mathrm{R}$ calculated for a normally distributed trait $\left(\mathrm{R}_{\text {normal }}\right)$ and an exponentially distributed trait $\left(\mathrm{R}_{\text {exponential }}\right)$. Variables defined in Methods.

after exposure to a predator). Fig. 5 plots $R$ calculated for the normal distribution divided by $R$ for the exponential against the ratio of the standard deviations. This ratio of the $R \mathrm{~s}\left(R_{\text {normal }} / R_{\text {exponential }}\right)$ is $>1$, meaning that use of the normal calculations on exponentially distributed data overestimates $R$. Overestimation is typically between one and two times the number of animals needed but can be much larger. As the difference between means increases, normal and exponential calculations agree less.

\section{Target-Trait Range Choice}

The choice of the target-trait range is also important to calculation of $R$. Biologists need to decide whether the target-trait range should include, for example, the fastest individuals, the slowest, or those of average speed. We demonstrated calculations for trait ranges symmetric about the mean and considered both tails of a distribution (lower tail for exponential, upper tail for beta). For the example of refuge use, increased use could indicate a higher chance of survival in the wild. Therefore, we chose a target-trait range that includes animals that spend more time in a refuge after exposure to a predator. If the data were observations of flounder swimming in the water column, fewer observations would indicate a higher chance of survival.

Though the traits of interest, such as vertical habitat use and time spent cryptically concealed or hiding, are similar for different taxa, the width of the target-trait range is potentially different. Species such as mice and some fishes are easy to breed, and their captive populations are large; in contrast, for larger animals there are relatively few releasable captive-bred animals and cost per individual is high. We would therefore choose a wider target-trait range (e.g., $k=2$ ) for lemurs than for flounders (e.g., $k=1$ ). To determine $R$ for increasing conservative release criteria, trait ranges of decreasing widths might be considered.

\section{Use of the Release Ratio}

Our calculations were developed for populations in which the release population is more variable than the baseline population. Not all behavioral or morphological traits will show increased variance with generations in captivity. Captivity can also exert strong directional selection on certain traits such as docility (Archer 1973; Price 1998). Interestingly, increased variance is actually desirable in release populations that experience directional selection and extreme changes in mean trait expression (Fig. 2a). If trait means shift without increasing variance, few to none of the captive-bred individuals will exhibit traits in the target range. Release ratios can also be developed for these situations.

Release-ratio calculation is useful if measurements cannot be taken on the actual individuals to be released. For example, measuring individual behaviors can be expensive and logistically difficult, or they can unnecessarily increase human contact with release individuals. In these cases, measurements can be taken on a surrogate population of unreleasable animals or a closely related taxon. For the Peromyscus example, we measured traits in the relatively abundant $P$. polionotus subgriseus and believe these traits are applicable to endangered subspecies of $P$. polionotus.

Choosing individual animals for release may impose additional artificial selection on the release population. In contrast, choice of the target-trait range does not affect the distribution of traits in the released animals; calculation of $R$ provides a multiplying factor only to ensure that sufficient release animals exhibit wildlike behavioral and morphological traits. If the traits of reintroduced animals shift to become more similar to wild animals on release, then the release ratio will be a conservative estimate of the release size needed. Calculation of the release ratio can also provide guidance on the value of training captive animals prior to release: the relative decrease in $R$ for shifting release distributions closer to wild distributions could serve as a measure of the value of a training procedure.

The release ratio is not only a useful tool for determining actual release numbers, but it also provides valuable information to help weigh the potential benefits of a reintroduction against its costs. Reintroduction programs are incredibly expensive (Kleiman et al. 1991), and reintroducing too few or too many individuals wastes resources. The fact that sufficient numbers of animals need to be released for a program to succeed may be self-evident to many conservation biologists. Less intuitive, however, is the problem of reintroducing too many. Griffith et al. (1989) found that program success is an asymptotically increasing function of the number of release animals. 
Additional animals were therefore superfluous. Calculation of $R$ for several traits will help determine a minimum and maximum number of animals needed for success.

The release ratio is the first attempt to incorporate quantitative behavioral and morphological change into the determination of release population size. To maximize the applicability of $R$, we need to further develop these calculations. For example, our calculations estimate $R$ on a trait-by-trait basis. For the oldfield mouse, calculating $R$ for different traits yielded similar values, but this may not always be the case. We are developing methods to calculate $R$ using the joint distribution of multiple traits. This will allow us to incorporate correlation between trait values into the release ratio.

We need more studies that compare wild and captivebred behaviors and morphologies across a wide range of taxa. Höhn et al.'s (2000) study of agonistic strategies of free-ranging and captive Eastern gray kangaroos (Macropus giganteus) is a good example of the type of comparative studies needed in reintroduction biology. They found that wild individuals spent more time feeding and were alert more often than captive-bred animals. Without knowledge of which traits are most critical to survival for gray kangaroos, these behaviors would be a good starting point for release-ratio calculations for Macropus. Such studies can serve as models for research programs designed to reveal the differences between wild and captivebred animals. This area of research should be pursued and expanded, not only to determine the effectiveness of captive breeding as a conservation tool, but also to understand basic evolutionary change in small populations.

\section{Acknowledgments}

We acknowledge financial and logistical support for this project from the following institutions: Chicago Zoological Society, Denver Zoological Foundation, Pittsburgh Zoo, Cleveland Metroparks Zoo, University of Michigan's Rackham Graduate School, University of Michigan's School of Natural Resources and Environment, U.S. Forest Service/Ocala National Forest, Edna Bailey Sussman Fund, and Sigma Xi. In addition, we thank T. Sullivan, S. Margulis, G. Rabb, B. Miller, R. Reading, and D. Kleiman for encouraging and supporting this research; J. Strickland with the Peromyscus Stock Center for all of her help sorting generations and specimens; and C. Howes for unending editorial support. Special thanks goes to B. Lacy, G. Alaks, A. Walsh, B. Low, T. Root, J. Mitani, P. Myers, A. Steel, J. Reynolds, and two anonymous reviewers for their time and attention.

\section{Literature Cited}

Archer, J. 1973. Tests for emotionality in rats and mice: a review. Animal Behaviour 21:205-235.

Arnold, S. J. 1995. Monitoring quantitative genetic variation and evolu- tion in captive populations. Pages 295-317 in J. D. Ballou, M. Gilpin, and T. J. Foose, editors. Population management for survival and recovery. Columbia University Press, New York.

Ballou, J. D., and T. J. Foose. 1996. Demographic and genetic management of captive populations. Pages 263-283 in D. G. Kleiman, M. E. Allen, K. V. Thompson, and S. Lumpkin, editors. Wild mammals in captivity: principles and techniques. University of Chicago Press, Chicago.

Beck, B. B. 1995. Reintroduction, zoos, conservation, and animal welfare. Pages 155-163 in B. G. Norton, M. Hutchins, E. F. Stevens, and T. L. Maple, editors. Ethics on the ark: zoos, animal welfare, and wildlife conservation. Smithsonian Institution Press, Washington, D.C.

Biggins, D. 2000. Predation on black-footed ferrents (Mustela nigripes) and Siberian polecats (M. eversmannii): conservation and evolutionary implications. Ph.D. dissertation. Colorado State University, Fort Collins.

Britt, A., A. Katz, and C. Welch. 1999. Project Betampona: conservation and re-stocking of black and white ruffed lemurs (Varecia variegata variegata). Seventh world conference on breeding endangered species: linking zoo and field research to advance conservation. Cincinnati Zoo and Botanical Garden, Cincinnati.

Chivers, D. J. 1991. Guidelines for re-introductions: procedures and problems. Symposium of the Zoological Society of London 62:8999.

Darwin, C. R. 1868. The variation of animals and plants under domestication. Johns Hopkins University Press, Baltimore, Maryland.

Everitt, B. S. 1998. The Cambridge dictionary of statistics. Cambridge University Press, Cambridge, United Kingdom.

Ford, M. J. 2002. Selection in captivity during supportive breeding may reduce fitness in the wild. Conservation Biology 16:815-825.

Frankham, R., H. Hemmer, O. Ryder, E. Cothran, M. Soulé, N. Murray, and M. Snyder. 1986. Selection in captive populations. Zoo Biology 5:127-138.

Frantzen, M. A. J., J. W. H. Ferguson, and M. S. de Villiers. 2001. The conservation role of captive African wild dogs (Lycaon pictus). Biological Conservation 100:253-260.

Ginsberg, J. R. 1994. Captive breeding, reintroduction and the conservation of canids. Pages 365-383 in P. J. S. Olney, G. M. Mace, and A. T. C. Feistner, editors. Creative conservation: interactive management of wild and captive animals. Chapman \& Hall, London.

Griffith, B., J. M. Scott, J. W. Carpenter, and C. Reed. 1989. Translocation as a species conservation tool: status and strategy. Science 245:477480.

Höhn, M., M. Kronschnabl, and U. Ganslosser. 2000. Similarities and differences in activities and agonistic behavior of male Eastern grey kangaroos (Macropus giganteus) in captivity and the wild. Zoo Biology 19:529-539.

Holler, N. R., D. W. Mason, R. M. Dawson, T. Simons, and M. C. Wooten. 1989. Reestablishment of the Perdido Key beach mouse Peromyscus polionotus trissyllepsis on Gulf Islands National Seashore, Alabama, USA. Conservation Biology 3:397-404.

Kellison, G. T, D. B. Eggleston, and J. S. Burke. 2000. Comparative behaviour and survival of hatchery-reared versus wild summer flounder (Paralichthys dentatus). Canadian Journal of Fisheries and Aquatic Sciences 57:1870-1877.

Kleiman, D. G. 1989. Reintroduction of captive mammals for conservation: guidelines for reintroducing endangered species into the wild. BioScience 39:152-161

Kleiman, D. G., B. B. Beck, A. Baker, J. D. Ballou, L. Dietz, and J. Dietz. 1990. The conservation program for the golden lion tamarin, Leontopithecus rosalia. Endangered Species Update 8:82-85.

Kleiman, D. G., B. B. Beck, J. M. Dietz, and L. A. Dietz. 1991. Costs of a reintroduction and criteria for success: accounting and accountability in the golden lion tamarin conservation program. Symposia of the Zoological Society of London 62:125-142.

Kreger, M. 2003. Behavioral profiles of the captive juvenile Whooping Crane (Grus americana) as an indicator of reintroduction 
behavior and survival. Ph.D. dissertation. University of Maryland, College Park.

Kummer, H., and F. Kurt. 1965. A comparison of social behavior in captive and wild hamadryas babbons. Pages 65-80 in H. Vagtborg, editor. The baboon in medical research. University of Texas Press, Austin.

Lacy, R. C. 1987. Loss of genetic diversity from managed populations: interacting effects of drift, mutation, selection, and population subdivision. Conservation Biology 1:143-159.

Lickliter, R., and J. W. Ness. 1990. Domestication and comparative psychology: status and strategy. Journal of Comparative Psychology 104:211-218.

Lindburg, D. G. 1992. Are wildlife reintroductions worth the cost? Zoo Biology 11:1-2.

Manly, B. F J. 1997. Randomization, bootstrap and Monte Carlo methods in biology. Second edition. Chapman \& Hall, New York.

Marchetti, M. P. and G. A. Nevitt. 2003. Effects of hatchery rearing on brain structures of rainbow trout, Oncorhynchus mykiss. Environmental Biology of Fishes 66:9-14.

McPhee, M. E. 2002. Effects of captivity on behavior and morphology in the oldfield mouse, Peromyscus polionotus subgriseus. Ph.D. dissertation. University of Michigan, Ann Arbor.

McPhee, M. E. 2004. Generations in captivity increases behavioral variance: Considerations for captive breeding and reintroduction programs. Biological Conservation 115:71-77.

Miller, B., D. Biggin, C. Wemmer, R. Powell, L. Calvo, L. Hanebury, and T. Wharton. 1990. Development of survival skills in captiveraised Siberian polecats (Mustela eversmanni). II. Predator avoidance. Journal of Ethology 8:95-104.

Miller, B., D. Biggins, D. Hanebury, and A. Vargas. 1994. Reintroduction of the black-footed ferret (Mustela nigripes). Pages 455-464 in P. J. S. Olney, G. M. Mace, and A. T. C. Feistner, editors. Creative conservation: interactive management of wild and captive animals. Chapman \& Hall, London.

Mills, M. G. L. 1999. Biology, status and conservation with special reference to the role of captive breeding in the African wild dog (Lycaon pictus). Seventh world conference on breeding endangered species: linking zoo and field research to advance conservation. Cincinnati Zoo and Botanical Garden, Cincinnati.

Myers, P., B. L. Lundrigan, B. W. Gillespie, and M. L. Zelditch. 1996. Phenotypic plasticity in skull and dental morphology in the prairie deer mouse (Peromyscus maniculatus bairdii). Journal of Morphology 229:229-237.

Nesbitt, S. A., M. J. Folk, K. A. Sullivan, S. T. Schwikert, and M. G. Spald- ing. 2001. An update of the Florida Whooping Crane release project through June 2000. Proceedings of the North American Crane Workshop 8:62-72.

Olla, B. L., M. W. Davis, C. H. Ryer. 1998. Understanding how the hatchery environment represses or promotes the development of behavioral survival skills. Bulletin of Marine Science 62:531-550.

Price, E. O. 1970. Differential reactivity of wild and semi-domestic deermice (Peromyscus maniculatus). Animal Behaviour 18:747-752.

Price, E. O. 1984. Behavioral aspects of animal domestication. The Quarterly Review of Biology 59:1-32.

Price, E. O. 1998. Behavioral genetics and the process of animal domestication. Pages 31-65 in T. Grandin, editor. Genetics and the behavior of domestic animals. Academic Press, San Diego.

Rowell, T. E. 1967. A quantitative comparison of the behavior of a wild and a caged baboon group. Animal Behaviour 15:499-509.

Statistical Sciences. 1999. S-Plus guide to statistical and mathematical analysis. Version S-Plus 2000. Professional release 2. Statscience, MathSoft, Seattle.

Stuart, S. N. 1991. Re-introductions: to what extent are they needed? Symposium of the Zoological Society of London 62:27-37.

Stunz, G. W., and T. J. Minello. 2001. Habitat-related predation on juvenile wild-caught and hatchery-reared red drum Sciaenops ocellatus (Linnaeus). Journal of Experimental Marine Biology and Ecology 260:13-25.

Sundström, L. F, and J. I. Johnsson. 2001. Experience and social environment influence the ability of young brown trout to forage on live novel prey. Animal Behaviour 61:249-255.

U.S. Fish \& Wildlife Service (USFWS). 1987. Recovery plan for the Choctawhatchee, Perdido Key and Alabama beach mouse. USFWS, Atlanta.

U.S. Fish \& Wildlife Service (USFWS). 1993. Recovery plan for the Anastasia Island and southeastern beach mouse. USFWS, Atlanta

U.S. Fish \& Wildlife Service (USFWS). 2001. Threatened and endangered species system. Division of Endangered Species, USFWS, Washington, D.C. Available from http://ecos.fws.gov/tess_public/ tesswebpageviplisted ? code $=$ V8listings $=0$, (accessed August 2003).

Wallace, M. P. 1994. Control of behavioral development in the context of reintroduction programs for birds. Zoo Biology 13:491-499.

Wooten, M. 2001. The beach mouse info page. Department of Biological Sciences, Auburn University, Auburn, Alabama. Available from http://www.ag.auburn.edu/ mwooten/main.html\#A1.1 (accessed October 2001).

Zar, J. H. 1999. Biostatistical analysis. Fourth edition. Prentice Hall, Upper Saddle River, New Jersey.

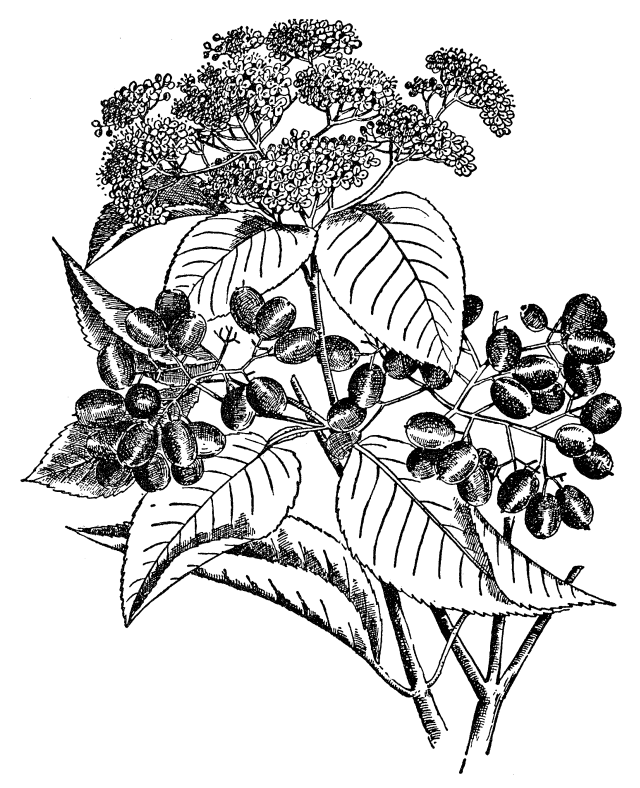

